\title{
Discordant effects of anti-VLA-4 treatment before and after onset of relapsing experimental autoimmune encephalomyelitis
}

\author{
Bradley E. Theien, ${ }^{1}$ Carol L. Vanderlugt, ${ }^{1}$ Todd N. Eagar, ${ }^{1}$ Cheryl Nickerson-Nutter, ${ }^{2}$ \\ Remederios Nazareno, ${ }^{3}$ Vijay K. Kuchroo, ${ }^{3}$ and Stephen D. Miller ${ }^{1}$ \\ ${ }^{1}$ Department of Microbiology-Immunology and the Interdepartmental Immunobiology Center, \\ Northwestern University Medical School, Chicago, Illinois, USA \\ ${ }^{2}$ Biogen Inc., Cambridge, Massachusetts, USA \\ ${ }^{3}$ Center for Neurologic Diseases, Harvard University, Boston, Massachusetts, USA
}

Address correspondence to: Stephen D. Miller, Department of Microbiology-Immunology, Northwestern University Medical School, 303 East Chicago Avenue, Chicago, Illinois 60611, USA. Phone: (312) 503-7674; Fax: (312) 503-1154; E-mail: s-d-miller@northwestern.edu.

Received for publication November 6, 2000, and accepted in revised form March 13, 2001.

\begin{abstract}
Initial migration of encephalitogenic $\mathrm{T}$ cells to the central nervous system (CNS) in relapsing experimental autoimmune encephalomyelitis (R-EAE), an animal model of multiple sclerosis (MS), depends on the interaction of the $\alpha 4$ integrin (VLA-4) expressed on activated T cells with VCAM-1 expressed on activated cerebrovascular endothelial cells. Alternate homing mechanisms may be employed by infiltrating inflammatory cells after disease onset. We thus compared the ability of anti-VLA-4 to regulate proteolipid protein (PLP) 139-151-induced R-EAE when administered either before or after disease onset. Preclinical administration of anti-VLA-4 either to naive recipients of primed encephalitogenic $T$ cells or to mice 1 week after peptide priming, i.e., before clinical disease onset, inhibited the onset and severity of clinical disease. In contrast, $\mathrm{Ab}$ treatment either at the peak of acute disease or during remission exacerbated disease relapses and increased the accumulation of $\mathrm{CD}^{+} \mathrm{T}$ cells in the CNS. Most significantly, anti-VLA-4 treatment either before or during ongoing R-EAE enhanced Th1 responses to both the priming peptide and endogenous myelin epitopes released secondary to acute tissue damage. Collectively, these results suggest that treatment with anti-VLA- $4 \mathrm{Ab}$ has multiple effects on the immune system and may be problematic in treating established autoimmune diseases such as MS.
\end{abstract}

J. Clin. Invest. 107:995-1006 (2001).

\section{Introduction}

Relapsing experimental autoimmune encephalomyelitis (R-EAE) is a CD4 ${ }^{+} \mathrm{T}$ cell-mediated disease characterized by inflammation and demyelination within the central nervous system (CNS) (1). In the SJL mouse, R-EAE, a disease model for multiple sclerosis (MS), can be induced by active immunization with the immunodominant epitope of proteolipid protein, PLP139-151, or by the transfer of peptide-specific T cells (2). This model is characterized by a moderate to severe acute paralytic phase followed by remission and subsequent relapses (2). Relapses are mediated by T-cell responses against endogenous myelin peptides recruited secondary to acute CNS damage, a process termed epitope spreading $(3,4)$. Tolerization with the PLP178-191 peptide during remission from acute PLP139-151-induced R-EAE inhibits development of clinical relapses confirming the predominant pathologic role of PLP178191-specific T cells in disease progression (4-6).

Elucidation of the mechanisms by which activated $\mathrm{T}$ cells cross the blood-brain barrier and gain entry to the CNS is of significant importance to the pathogenesis of R-EAE. The integrin $\alpha 4 \beta 1$, often referred to as the very late antigen-4 (VLA-4), has been shown to play an integral part in the homing of cells that induce disease (7-10). Interaction of VLA-4 with its ligand, VCAM-1, which is expressed on CNS endothelium, allows entry of encephalitogenic T cells into the CNS (7). Interfering with this interaction is postulated to have a potential beneficial therapeutic effects for many autoimmune diseases, including multiple sclerosis (MS).

In addition to its role in T-cell entry into the CNS, VLA-4 likely plays an important role in other immune functions. For example, VLA-4 may act as a costimulatory molecule on $\mathrm{T}$ cells and could therefore influence T-cell activation and differentiation (11-14). Furthermore, VLA-4 may have a role in collagen matrix reorganization in response to injury or inflammation (15), memory B-cell activation (16), and eosinophil and neutrophil migration into inflamed tissue $(17,18)$. In addition, VLA-4 interactions with either VCAM-1 or fibronectin have been shown to protect cells from apoptosis, possibly due to the upregulation of $\mathrm{Bcl}-2$, an anti-apoptotic regulatory protein (19-21).

Considering the complex role of VLA-4 in immune responses, we wanted to examine the effects of long- 
term treatment with the anti- $\alpha 4 \mathrm{mAb} \mathrm{PS} / 2$ begun either before or after the appearance of clinical symptoms in R-EAE. It is important to note that the $\alpha 4$ integrin can interact with $\beta 1$ and $\beta 7$ to form the heterodimers $\alpha 4 \beta 1$ and $\alpha 4 \beta 7$, both of which play a role in adhesion to CNS endothelium. PS/2 effectively blocks the functions of both of these heterodimers, including $\alpha 4 \beta 7$ interactions with MAdCAM-1, an additional adhesion molecule found on CNS endothelium, which may be important in the pathogenesis of R-EAE $(22,23)$. Previous studies showed that blocking VLA-4/VCAM-1 interaction with anti- $\alpha 4$ integrin at the time of disease induction inhibited initiation of both actively induced and adoptive $\operatorname{EAE}(7,9,10)$. Additional work has suggested that administering anti-VLA-4 may inhibit development of brain lesions in EAE and possibly MS $(24,25)$. In this study we compared the long-term effects of anti-VLA-4 treatment administered preclinically to treatment begun after the onset of clinical symptoms on clinical disease. In both treatment regimens, clinical disease and peripheral antigen-specific T-cell activation and differentiation was examined. We demonstrate that although preclinical administration of anti-VLA-4 effectively inhibited R-EAE induction, treatment with the anti-VLA- $4 \mathrm{mAb}$ PS/2 initiated after the appearance of clinical symptoms resulted in increased relapse rates, an augmentation of Th1 responses, and an enhancement of epitope spreading.

\section{Methods}

Animals. Six- to seven-week-old female SJL mice were obtained from Harlan Bioproducts for Science (Indianapolis, Indiana, USA). Mice were housed under barrier conditions, and paralyzed mice were afforded easier access to food and water.

Peptides. PLP139-151 (HSLGKWLGHPDKF), PLP178191 (NTWTTCQSIAFPSK), and MBP84-104 (VHFFKNIVTPRTPPPSQGKGR) were synthesized by the peptide facility at the University of North Carolina, Chapel Hill, North Carolina, USA. Amino acid composition of these peptides was verified by mass spectrometry and purity (>97\%) was confirmed by mass spectroscopy at the Michigan State University Biotechnology Center, East Lansing, Michigan, USA. Active induction of EAE. Mice were subcutaneously immunized with $100 \mu \mathrm{l}$ of CFA emulsion containing 200 $\mu \mathrm{g}$ of Mycobacterium tuberculosis H37Ra (Difco Laboratories, Detroit, Michigan, USA) and $40 \mu \mathrm{g}$ of PLP139-151 distributed over three spots across the flank.

Adoptive transfer of EAE. Short-term PLP139-151-specific T-cell lines were generated by immunizing SJL mice with PLP139-151 peptide in CFA. Ten days later, draining lymph node $T$ cells were cultured with 100 $\mu \mathrm{g} / \mathrm{ml}$ of PLP139-151 peptide in HL-1 (serum free) medium. Four days later the cells were harvested, and live cells were obtained by Ficoll-Hypaque gradient separation and injected into naive SJL recipients. Each recipient received $10^{7}$ PLP139-151-activated T cells and one injection of $200 \mu \mathrm{g}$ pertussis toxin intravenously.
To test the effect of VLA-4 blockade, the recipients received anti-VLA-4 Ab $(150 \mu \mathrm{g})$ or a control Ab intraperitoneally every other day as described in Results. The animals were observed and scored for the development of EAE, as described below.

In vivo Ab treatment. $\mathrm{PS} / 2$, a monoclonal rat $\operatorname{IgG}_{2 \mathrm{~b}} \kappa$ anti-mouse $\alpha 4$ (CD49d) integrin IgG was supplied by Biogen Inc. (Cambridge, Massachusetts, USA). The Ab is commercially available from Southern Biotechnology Associates Inc. (Birmingham, Alabama, USA). Purified rat IgG control Ab was supplied by PharMingen (San Diego, California, USA). The endotoxin level for all experimental Ab's was less than or equal to $0.01 \mathrm{ng} / \mathrm{\mu g}$ of protein. Mice were treated nine times (three times per week for 3 consecutive weeks) with $75 \mu \mathrm{g}$ control rat Ig (Zymed Laboratories Inc., South San Francisco, California, USA) or PS/2 Ab administered intraperitoneally in a total volume of $100 \mu$ l. Treatment was initiated before disease onset (day 7), at the peak of acute disease (day 14), or during the first remission (day 25).

Clinical evaluation. Clinical severity was assessed on a 0 to 5 scale as follows: grade 0 , no abnormality; grade 1 , limp tail or hind-limb weakness; grade 2, limp tail and hind-limb weakness (waddling gait); grade 3 , partial hind-limb paralysis; grade 4, complete hind-limb paralysis; and grade 5, moribund. A relapse was defined as a sustained increase (more than 2 days) in at least one full grade in clinical score after the animal had improved previously at least a full clinical score and had stabilized for at least 2 days. The data are plotted as the mean clinical score for all animals in a particular treatment group or as the relapse rate (total number of relapses in a group divided by the total number of mice in that group).

Preparation of tissue for immunobistochemistry. At day 14 and day 26 after priming (for mice treated preclinically) and day 20 and 33 after priming (for mice treated at peak of acute disease), two mice per time point were perfused with PBS and fresh $4 \%$ paraformaldehyde (Sigma Chemical Co., St. Louis, Missouri, USA). Spinal cords and brains were dissected out and blocks of tissue were flash-frozen in OCT compound (Miles Laboratories, Elkhart, Indiana, USA) with liquid nitrogen. Tissue from the lower thoracic region of the spinal cord and the cerebellum and brainstem was sectioned at 6 $\mu \mathrm{m}$ on a Reichert-Jung 1800 cryotome (Leica Microsystems Inc., Deerfield, Illinois, USA) and mounted on Superfrost Plus electrostatically charged slides.

Immunobistochemistry. Slides were stained using Tyramide Signal Amplification (TSA) Direct Kit (NEN Life Science Products, Boston, Massachusetts, USA) according to the manufacturer's protocol. Tissue was thawed, air dried, and rehydrated in PBS. After catalyzing endogenous peroxidases in $0.3 \%$ hydrogen peroxide, nonspecific staining was blocked using an avidin/biotin blocking kit (Vector Labs, Burlingame, California, USA) in addition to the blocking reagent provided by the TSA kit. For CD4, CD8, B220, and VCAM-1 staining, slides were incubated with biotinylated anti-L3T4, anti-Ly-2, 
RA3-6B2, and 429 (MVCAM.A) (PharMingen), respectively, for 1 hour at room temperature. Sections were counterstained with $0.1 \mu \mathrm{g} / \mathrm{ml} \mathrm{4}$,6-diamidine-2phenylindole dihydrochloride (DAPI; Sigma Chemical Co.) and coverslipped with VECTASHIELD mounting medium (Vector Laboratories, Burlingame, California, USA). Tissue was examined with epifluorescence using a chroma triple-band filter (Chroma Technology Corp., Brattleboro, Vermont, USA).

Isolation of $m R N A$, first-strand cDNA synthesis, and RT$P C R$. At day 14 and day 26 after priming (for mice treated preclinically) and day 20 and 33 after priming (for mice treated at peak of acute disease), three mice per group were anesthetized and perfused through the left ventricle with $30 \mathrm{ml}$ of PBS. Spinal cords were extruded by flushing the vertebral canal with PBS and then rinsed in PBS. Tissues were forced through a 100-mesh stainless steel screen to give a single cell suspension and pelleted by centrifugation $(500 \mathrm{~g})$ for 5 minutes at $4^{\circ} \mathrm{C}$. The pellets were resuspended vigorously in $16 \mathrm{ml}$ of 4 $\mathrm{M}$ guanidinium isothiocyanate $/ 50 \mathrm{mM}$ Tris- $\mathrm{Cl}(\mathrm{pH}$ 7.5)/25 mM EDTA (Life Technologies Inc., Gaithersburg, Maryland, USA), and 1\% 2-mercaptoethanol and $0.5 \% N$-lauroylsarcosine (Sigma-Aldrich, St. Louis, Missouri, USA). Shearing of DNA was facilitated by forcing the resulting suspension repeatedly through a 23gauge needle. Total RNA was isolated by high-speed gradient centrifugation $(129,633 \mathrm{~g})$ of $8 \mathrm{ml}$ of lysate through a 3-ml 5.7 M CsCl pad using a SW41 swinging bucket rotor for 20 hours at $4{ }^{\circ} \mathrm{C}$. The resulting RNA pellet was resuspended to a final concentration of 1 $\mu \mathrm{g} / \mu \mathrm{l}$ with diethylpyrocarbonate-treated water and stored in aliquots at $-70^{\circ} \mathrm{C}$. First-strand cDNA was generated from $2 \mu \mathrm{g}$ total RNA with Advantage-RT Kit (CLONTECH Laboratories Inc., Palo Alto, California, USA) using 20 pmol oligo(dT) primer, per the manufacturer's provided protocol, in a total volume of $20 \mu \mathrm{l}$. Following first-strand synthesis, each cDNA sample was brought to a final volume of $100 \mu \mathrm{l}$ with distilled water. Final PCR conditions included $50 \mathrm{mM} \mathrm{KCl}, 10$ $\mathrm{mM}$ Tris-Cl (pH 8.3), 2.5 to $5 \mathrm{mM} \mathrm{MgCl}_{2}, 2 \mathrm{mM}$ dNTP, 100 pmol of each $5^{\prime}$ and $3^{\prime}$ gene-specific primer, $1 \mathrm{U}$ Taq polymerase (QIAGEN Inc., Chatsworth, California, USA), and 5 to $10 \mu \mathrm{l}$ diluted cDNA. The primers were synthesized by Life Technologies Inc. and amplify both the competitor plasmid and wild-type cDNA. Expression of IL-4 (5'CAT CGG CAT TTT GAA CGA GGT CA, 3' CTT ATC GAT GAA TCC AGG CAT CG), IL-5 (5'GAA AGA GAC CTT GAC ACA GCT G, 3'GAA CTC TTG CAG GTA ATC CAG G), IL-10 (5'CCA GTT TTA CCT GGT AGA AGT GAT G, 3'TGT CTA GGT CCT GGA GTC CAG CAG ACT CAA), IFN- $\gamma\left(5^{\prime}\right.$ CTT GGA TAT CTG GAG GAA CTG GC, $3^{\prime}$ GCG CTG GACCTGTGGGTTGTTGA), TNF- $\alpha$ ( $5^{\prime}$ GTT CTA TGG CCC AGA CCC TCA CA, 3'TAC CAGGGTTTGAGCTCAGC), LT (5'ATG ACA CTG CTC GGC CGT CTC CA, 3'CAC TGG TGG GGA TCA GGA GGG AG), and P-selectin ( $5^{\prime}$ GTC CAC GGA GAG TTT GGT GT, 3'AAG TGG TGT TCG GAC CAA $A G)$ genes were examined. Cycling conditions were $94^{\circ} \mathrm{C}$ for 40 seconds, $60^{\circ} \mathrm{C}$ for 20 seconds, and $72^{\circ} \mathrm{C}$ for 40 seconds, for a total of 30 cycles, linked to a final $72^{\circ} \mathrm{C}$ extension program for 3 minutes and then to a final $4^{\circ} \mathrm{C}$ soak program. PCR products were run on an ethidium bromide containing $2 \%$ agarose gel and illuminated using an ultraviolet light source, then photographed using Polaroid type 667 film.

In vitro T-cell proliferation and cytokine assays. Spleen and draining lymph node cells (axillary and inguinal) were obtained from three animals treated preclinically (at day 13 , after three treatments, and day 26 , after nine treatments) and at peak of acute disease (at day 20, after three treatments, and day 33, after nine treatments). For proliferation, cells were dissociated and cultured in 96well microtiter plates (Corning-Costar, Cambridge, Massachusetts, USA) at a density of $5 \times 10^{5}$ viable cells/well in a total volume of $200 \mu \mathrm{l}$ peptide DMEM supplemented with $10 \%$ FCS (Sigma Chemical Co.), 100 $\mathrm{U} / \mathrm{ml}$ penicillin (Life Technologies Inc.), $100 \mu \mathrm{g} / \mathrm{ml}$ streptomycin (Life Technologies Inc.), and $2 \mathrm{mM}$ L-glutamine (Life Technologies Inc.). Cells were cultured at $37^{\circ} \mathrm{C}$ in $100 \%$ humidity and $5 \% \mathrm{CO}_{2}$ in the presence or absence (background) of varying concentrations of either PLP139-151 or PLP178-191. As a control, concanavalin A (Sigma Chemical Co.) was used at a concentration of $5 \mu \mathrm{g} / \mathrm{ml}$. Cultures were pulsed with $1 \mu \mathrm{Ci}$ of ${ }^{3} \mathrm{H}$-thymidine $\left({ }^{3} \mathrm{H}-\mathrm{TdR}\right.$; ICN Radiochemicals Inc., Irvine, California, USA) after 72 hours, harvested at 92 hours, and ${ }^{3} \mathrm{H}-\mathrm{TdR}$ uptake was detected using a Packard Topcount microplate scintillation counter (Packard Instrument Co., Meriden, Connecticut, USA). Results are expressed as mean of triplicate cultures \pm SEM. For cytokine analysis, $2.5 \times 10^{6}$ spleen and lymph node cells were in a total volume of $1 \mathrm{ml}$ supplemented DMEM and $25 \mu \mathrm{M}$ PLP139-151, PLP178-191, or DMEM alone. Supernatants were harvested at 24 and 48 hours and analyzed for IL-2, IL-4, and IFN- $\gamma$ by capture ELISA. ELISA reagents were purchased from Endogen Inc. (Woburn, Massachusetts, USA) and were used according to the manufacturer's protocol. Briefly, 96-well Nunc Maxisorb plates were coated overnight with anticytokine capture $\mathrm{Ab}$, followed by washing. Cytokine standards and samples were added to coated wells and were incubated at $20^{\circ} \mathrm{C}$ overnight and washed. Biotinylated anti-cytokine $\mathrm{Ab}$ was added, followed by washing and the addition of streptavidin-horseradish peroxidase (streptavidin-HRP) conjugate (DAKO, Glostrup, Denmark). Tetramethyl benzidine liquid substrate system was used. The plates were read at $450 \mathrm{nM}$.

Costimulation assays using Ab-coated microspheres. Fivemicrometer polystyrene sulfate-coated latex microspheres $\left(10^{7} / \mathrm{ml}\right.$; Interfacial Dynamics Corp., Portland, Maine, USA), were conjugated with $0.5 \mu \mathrm{g} / \mathrm{ml}$ antiCD3, $20 \mu \mathrm{g} / \mathrm{ml}$ anti-CD28, and/or $2 \mu \mathrm{g} / \mathrm{ml}$ anti-VLA4 in PBS at $4^{\circ} \mathrm{C}$ for a minimum of 60 minutes. The concentration of $A b$ 's in all tubes was normalized to a total of $40 \mu \mathrm{g} / \mathrm{ml}$ using hamster control Ig. After incubation, beads were suspended in DMEM- 5 for 60 minutes at $37^{\circ} \mathrm{C}$ to block further conjugation, washed in DMEM5 , and plated in varying concentrations with naive 


\section{Figure 1}

Anti-VLA-4 inhibits induction of, but exacerbates, ongoing clinical R-EAE. The indicated numbers of SJL mice were treated with rat control Ig or anti-VLA-4 (PS/2) beginning at day 7 (preclinical treatment), day 14 (acute-phase treatment), or day 24 (remission treatment) relative to priming with PLP139-151/CFA on day 0 . Three treatments per week for 3 consecutive weeks were administered. ( $\mathbf{a}$ and $\mathbf{c}$ ) Short-term experiments from which animals were taken after three treatments and after nine treatments for immune assays (see Figures 4-6). Animals in experiments shown in b, $\mathbf{d}, \mathbf{e}$, and $\mathbf{f}$ also received nine treatments but were observed for a longer period of time. The data are expressed as mean clinical score versus day after priming (a, $\mathbf{c}$, and $\mathbf{e})$ and as the long-term relapse rate $(\mathbf{b}, \mathbf{d}$, and $\mathbf{f})$. Data shown are representative of two to three separate experiments. AValues for the PS/2-treated mice are either significantly above or below those of the control Ig-treated mice; $P<0.05$.

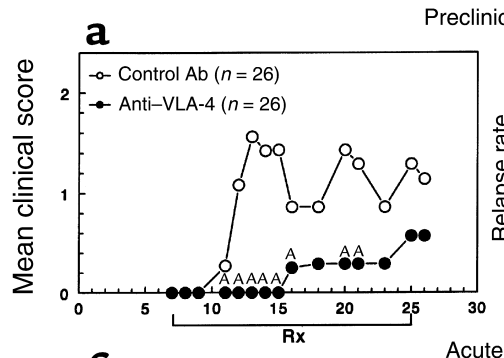

Preclinical treatment
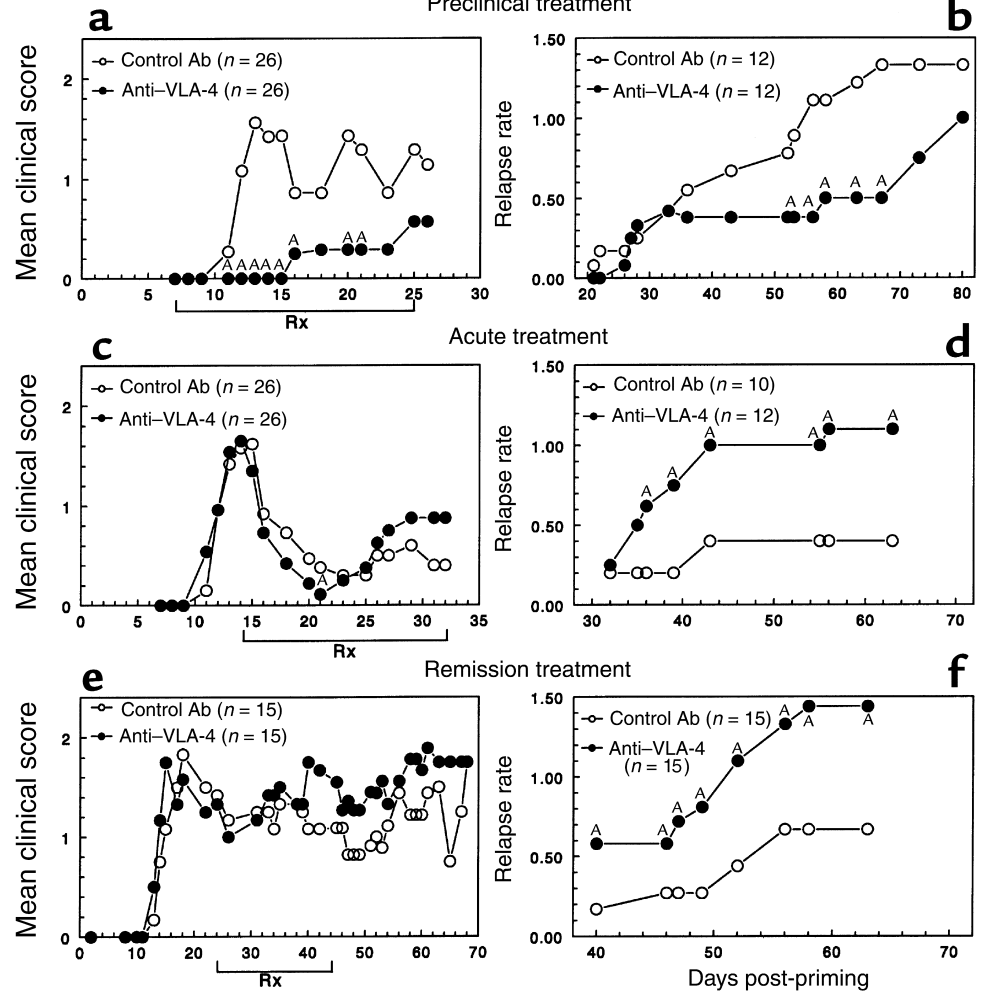

$\mathrm{BALB} / \mathrm{c}$ splenic $\mathrm{CD} 4^{+} \mathrm{T}$ cells. Cells $\left(5 \times 10^{4}\right.$ cells/well $)$ were cultured in 96-well plates with an equal number of Ab-conjugated microspheres. Cultures were pulsed with $1 \mu \mathrm{Ci}$ or ${ }^{3} \mathrm{H}-\mathrm{TdR}$ at culture initiation and harvested 72 hours later.

Flow-cytometric analysis. FITC-conjugated $\mathrm{mAbs}$ to CD80 and CD86, biotinylated mAb to CD29, allophycocyanin-conjugated $\mathrm{mAb}$ to $\mathrm{CD} 4$, and phycoerythrinconjugated (PE-conjugated) $\mathrm{mAb}$ to $\mathrm{CD} 19$ were purchased from PharMingen. Isolated spleen and CNS cells were prepared for flow cytometry by incubating cells with $\mathrm{mAb}$ followed by PBS washes. Data collection and analyses were performed on a FACScalibur flow cytometer (Becton Dickinson Immunocytometry Systems, Mountain View, California, USA).

Statistical Analysis. Differences in clinical scores and delayed-type hypersensitivity (DTH) between control and treatment groups were analyzed by Student's $t$ test. Differences in relapse rates between control and treatment groups were analyzed by $\chi$-square. $P$ values less than 0.05 were considered significant.

\section{Results}

Treatment with anti-VLA-4 mAb initiated before disease onset inhibits clinical signs of R-EAE. Previous studies suggest that VLA-4 (CD49d) interaction with its ligand VCAM1 (CD106) is important for the induction of EAE (7) and that surface expression of the $\alpha 4$ integrin by $\mathrm{CD} 4^{+}$ $\mathrm{T}$ cells is required for their entry into CNS parenchyma $(9,26)$. Treatment with $\mathrm{mAb}$ to $\mathrm{CD} 49 \mathrm{~d}$, the $\alpha 4$ integrin, initiated at the time of priming, effectively inhibited clinical signs of $\operatorname{EAE}(7,9)$. We thus asked if anti-VLA-
4 (PS/2) treatment initiated at day 7 after priming, after the initial myelin-specific T-cell activation in the periphery but before clinical disease, would also inhibit onset of R-EAE (Figure 1a). By day 13 (after three treatments), 19 of 26 mice treated with the control $\mathrm{Ab}$ showed signs of R-EAE compared with 0 of 26 in the PS/2-treated group. By day 26 after priming (after the ninth and final treatment) only two out of the remaining seven animals in the PS/2-treated group exhibited clinical signs, with none relapsing (Figure 1a). Following a similar treatment regimen as the experiment shown in Figure 1a, but observing animals for a longer period of time, revealed disease protection is not long lasting (Figure 1b). Three separate experiments indicate that by day 80 , the mean clinical score ( 1.25 for PS $/ 2$ vs. 0.89 for controls) and the relapse rate ( 1.00 for PS/ 2 vs. 1.33 for controls) in both PS/2- and control-treated groups were similar. To determine whether anti-VLA$4 \mathrm{mAb}$ treatment affected induction of the encephalitogenic $\mathrm{T}$ cells or their ability to traffic, anti-VLA-4 $\mathrm{mAb}$ was also administered to recipients after the transfer of encephalitogenic PLP139-151-specific Tcell lines. Interestingly, treatment after adoptive transfer also significantly delayed expression of clinical signs of disease (Figure 2). This treatment was more effective if therapy was instituted within 1 day (Figure 2a) after the transfer of encephalitogenic $T$ cells and again, as in active EAE, was not long lasting.

Preclinical treatment with anti-VLA-4 mAb inbibits mononuclear cell infiltration and expression of proinflammatory cytokine $m R N A$ in the CNS. Immunohistochemical examination of mice treated with PS/2 from day 7 (Fig- 


\section{Figure 2}

Anti-VLA-4 treatment of naive recipients provides short-term protection from expression of adoptive REAE. Ten recipient mice per group were treated with control Ig (days 1, 3, 5, 7, and 9) or with anti-VLA4 relative to the transfer of $5 \times 10^{6}$ PLP139-151-specific lymph node T-cell blasts on day 0 . Anti-VLA-4 was administered on either days 1, 3, 5, 7, and 9 (a); days 3 and 5 (b); days 5 and 7 (c); or days 7 and 9 (d). ${ }^{A}$ Mean clinical scores of the PS/2-treated mice were significantly less than those of the control Igtreated mice; $P<0.05$ a

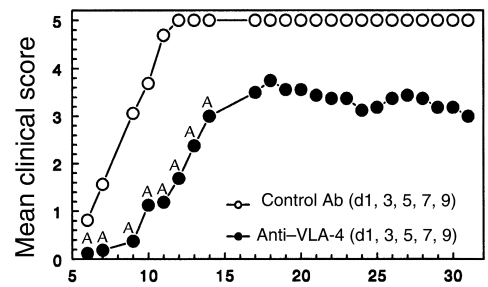

C

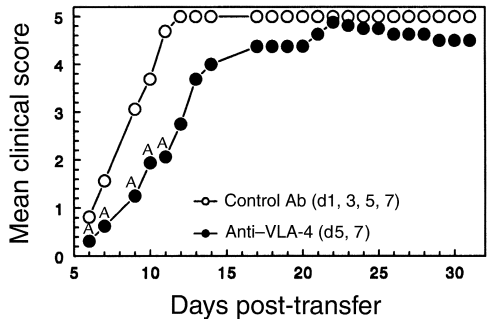

b

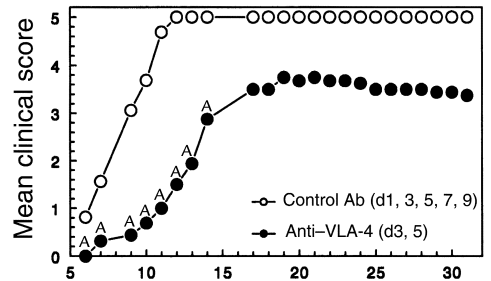

d

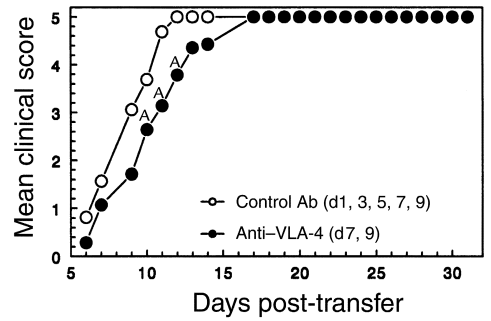

ure 1a) revealed an absence of $\mathrm{CD} 4^{+}$cells in the cerebellum, brainstem, and spinal cord (Figure 3c) at day 13 (after three treatments) and day 26 (after nine treatments, data not shown) and appeared similar to the naive controls (Figure 3a). In addition, $\mathrm{CD}^{+}, \mathrm{B} 220^{+}$ (expressed on B cells), and $\mathrm{F} 4 / 80^{+}$(a marker for macrophages) cells were absent in the CNS at both of these time points in anti-VLA-4-treated animals. This was in contrast to control Ab-treated mice, which displayed massive influx of $\mathrm{CD}^{+} \mathrm{T}$ cells into the cerebellum, brainstem, and spinal cord (Figure 3b) on day 13 (peak of acute phase) and also showed a substantial $\mathrm{CD}^{+}, \mathrm{B} 220^{+}$, and $\mathrm{F} 4 / 80^{+}$cellular influx at day 13 . CNS flow-cytometric analysis of anti-VLA-4-treated animals confirmed the lack of T and B lymphocytes in the CNS on day 14 after priming. At this time point, spinal cords of control $\mathrm{Ab}$-treated animals yielded large numbers of these infiltrating inflammatory cells (data not shown). At the peak of acute phase (day 13) control-treated animals exhibited upregulated gene expression of Th1 cytokines IFN- $\gamma$, TNF- $\alpha$, and lymphotoxin (LT) in the spinal cord. In contrast, genes for these cytokines were not expressed in the CNS of PS/2-treated mice. No IL4 or IL-5 message was detected at this time point for either group, and IL-10 message was also markedly reduced in the PS/2-treated animals (data not shown). These data correlate with the lack of CNS infiltration in the PS/2-treated mice at this time. By day 26, PS/2treated mice showed slightly increased IFN- $\gamma$ expression in the CNS compared with that of controls, which were in remission, and similar TNF- $\alpha$ expression. Since we have shown previously that gene expression of proinflammatory cytokines in the CNS is upregulated before disease onset (27), it is likely that one of the asymptomatic PS/2-treated animals sacrificed at this time was about to develop R-EAE (Figure 1a). No LT, IL-4, or IL-5 message was detected for either group, and IL-10 was expressed at low levels in both groups.

Preclinical treatment with anti-VLA-4 does not interfere with peripheral T-cell activation and Th1 differentiation. Tcell proliferation and secretion of proinflammatory cytokines from the experiment indicated in Figure 1a were assessed to determine the potential effects of preclinical treatment with anti-VLA-4 on T-cell priming
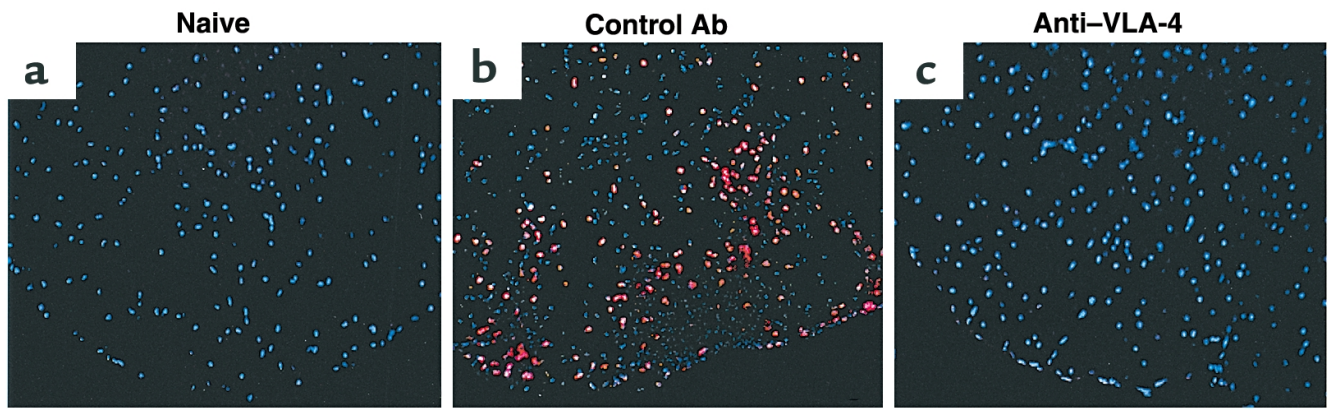

Figure 3

Preclinical administration of anti-VLA-4 blocks infiltration of CD4 ${ }^{+}$T cells into the CNS. Lower thoracic spinal cord, cerebellar, and brainstem tissue sections from representative animals of the treatment groups described in Figure 1a were examined for infiltration of inflammatory cells on day 13 after immunization. Three treatments of control Ab or anti-VLA-4 had been given by this time point. DAPI, in blue, stains all cells; $\mathrm{CD}^{+}$cells are marked in red. (a) Spinal cord $\mathrm{CD} 4^{+}$infiltrate in a naive animal. (b) Spinal cord CD4+ infiltrate in a control Igtreated animal. (c) Spinal cord CD4+ infiltrate in an anti-VLA-4-treated animal. All sections are $6 \mu \mathrm{m}$ thick. $\times 100$. 

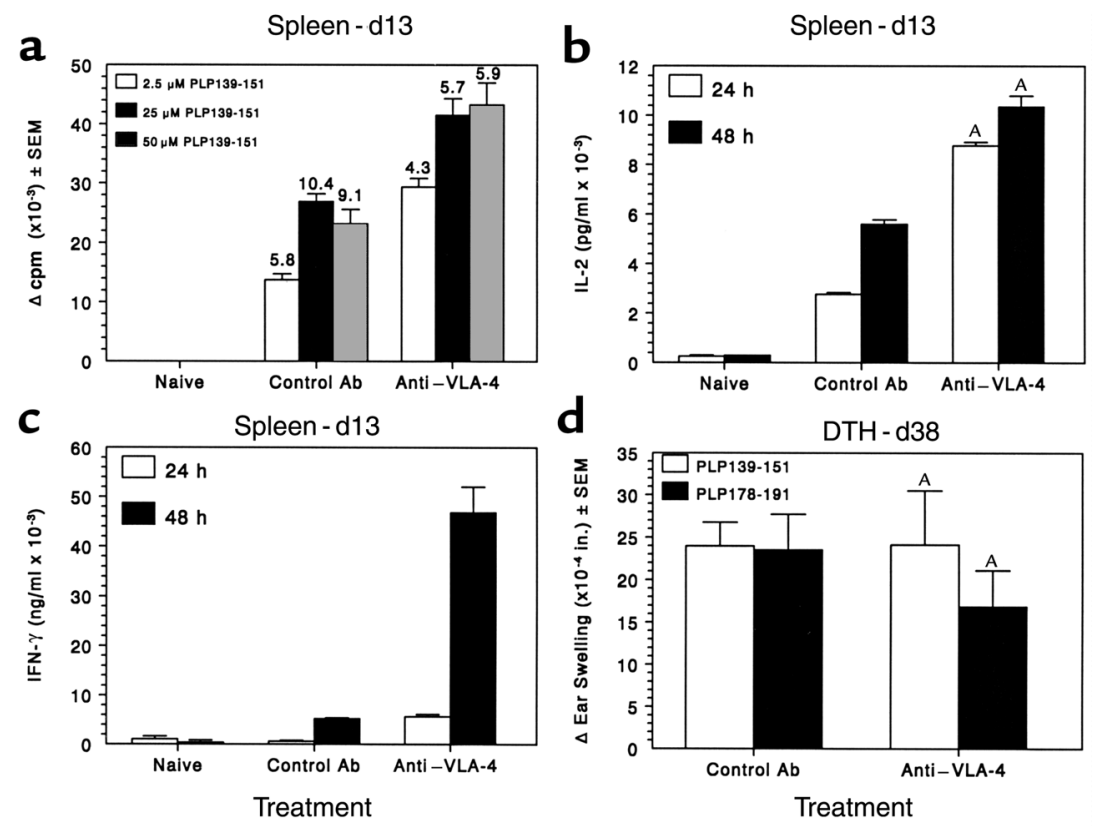

Figure 4

Preclinical administration of anti-VLA-4 does not inhibit activation of peripheral PLP139-151-specific T-cell responses. Splenic lymphocytes from three mice per group were harvested day 13 after immunization and tested for PLP139-151-specific proliferative and Th1 cytokine responses. Three treatments with either anti-VLA- 4 or control Ab had been administered by this time point. (a) Viable cells $\left(5 \times 10^{5} /\right.$ well $)$ were cultured with the indicated concentrations of PLP139-151 for 4 days. Cultures were pulsed with ${ }^{3} \mathrm{H}-\mathrm{TdR} 20$ hours before harvest. Data are presented as $\Delta \mathrm{cpm}\left({ }^{3} \mathrm{H}-\mathrm{TdR}\right.$ incorporation in cultures containing peptide antigen, ${ }^{3} \mathrm{H}-\mathrm{TdR}$ incorporation in cultures containing medium). Stimulation indices ( ${ }^{3} \mathrm{H}-\mathrm{TdR}$ incorporation in cultures containing peptide antigen, ${ }^{3} \mathrm{H}-\mathrm{TdR}$ incorporation in cultures containing medium) are indicated above each bar. ${ }^{3} \mathrm{H}$-TdR incorporation in cultures containing medium only were $2,849 \pm 183$ and $8,850 \pm 1,227$ for control and anti-VLA-4 groups, respectively. IL-2 (b) and IFN- $\gamma(\mathbf{c})$ levels in the supernatants of cultures harvested at 24 and 48 hours after stimulation with $25 \mu \mathrm{M}$ of PLP139-151 were determined by ELISA as described in Methods. (d) DTH responses to both the initiating PLP139151 peptide and the relapse-associated PLP178-191 peptide were evaluated in 4-5 mice treated with either control Ig or anti-VLA-4 at day 36 after immunization. Data represent the mean 24-hour change in ear thickness \pm SEM in response to challenge with $10 \mu \mathrm{g}$ of each peptide. ${ }^{A}$ IL-2 and IFN- $\gamma$ levels of the PS/2-treated mice were significantly more than those of the control Ig-treated mice; $P<0.01$.

and differentiation. Although activated T cells did not home to or accumulate in the CNS of PS/2-treated mice (Figure 3), activated Th1 cells were present in both the lymph node and the spleen of PS/2-treated mice. Splenic proliferative responses (Figure 4a) and secretion of the Th1 cytokines, IL-2 (Figure 4b) and IFN- $\gamma$ (Figure 4c), in response to the PLP139-151-priming epitope were increased on day 13 after priming when compared with animals treated with control Ab. By the end of the treatment regimen (day 26), the proliferative response to PLP139-151 in the lymph nodes was similar to that of controls, however splenic proliferation and IFN- $\gamma$ secretion were markedly lower for the PS/2treated animals (data not shown).

In long-term experiments (Figure 1b), DTH responses were assessed to measure in vivo Th1 activity. DTH responses to the priming PLP139-151 epitope on day 36 were also unaffected by early PS/ 2 treatment (Figure $4 d)$, regardless of clinical disease state of the mice. DTH responses to the relapse-associated PLP178-191 epitope correlated with the severity of acute disease and were absent only in animals with no myelin damage, i.e., mice that did not develop acute clinical signs of R-EAE. Therefore, preclinical treatment with PS/2 did not inhibit, but rather appeared to slightly enhance, the peripheral activation of autoantigen-specific Th1 cells. This strongly suggests that the amelioration of clinical disease in these PS/2-treated animals was due to the ability of anti-VLA-4 to block cellular migration to and/or inhibit accumulation of inflammatory cells within the CNS.

Treatment of ongoing R-EAE with anti-VLA-4 mAb exacerbates clinical relapses. Previous reports have shown that treatment with mAb to VLA-4 reversed clinical symptoms of EAE and resulted in the clearance of leukocytes from the CNS $(25,28)$. However, these studies focused on short-term results. Our data do confirm an initial reduction of disease symptoms in animals treated beginning at day 14 (peak of the acute phase) (Figure 1c). By day 20 (after three treatments), 5 of 21 of the remaining mice receiving anti-VLA-4 (PS/2) displayed clinical symptoms compared to 10 of 23 for the control group. This initial reduction, however, was followed by disease exacerbation during PS/2 treatment (Figure 1c). However, this pattern of disease exacerbation and increased relapse rate is shown more clearly in separate experiments focusing on the long-term observation of animals (Figure 1d). In addition, mice treated from dis- 
ease remission (day 24) also display exacerbated R-EAE (Figure 1e) during PS/2 treatment, and these mice exhibited a significantly higher relapse rate (1.4 vs. 0.6$)$ through 65 days after disease induction (Figure 1f). Therefore, PS $/ 2$ treatment begun at the peak of acute phase or during the first remission ultimately results in enhanced number and severity of disease relapses.

Acute-phase treatment with anti-VLA-4 enhances proliferation and IFN- $\gamma$ secretion in response to the priming epitope and augments epitope spreading. PLP139-151-specific proliferative responses (Figure 5a) and IFN- $\gamma$ secretion (data not shown) of lymph node T cells on day 19 after priming were strikingly elevated in mice that had received three injections of anti-VLA-4 beginning on day 14 , at the peak of acute disease (Figure 1c). There was no significant difference in proliferation or cytokine secretion in the spleen at this time. Interestingly, this was at a time when PS/2-treated mice displayed a less severe clinical disease (Figure 1c). Flowcytometric analysis of CNS-infiltrating cells showed a significantly decreased number of infiltrating $\mathrm{CD}^{+} \mathrm{T}$ cells thus correlating with the decreased level of clinical disease observed at this time point. There was also decreased integrin $\beta 1$ (CD29) and B7-1 (CD80) expression on CNS-infiltrating cells. B7-2 (CD86) expression was low in the CNS at this time point for both groups (data not shown). Little difference in expression of these surface markers was observed by
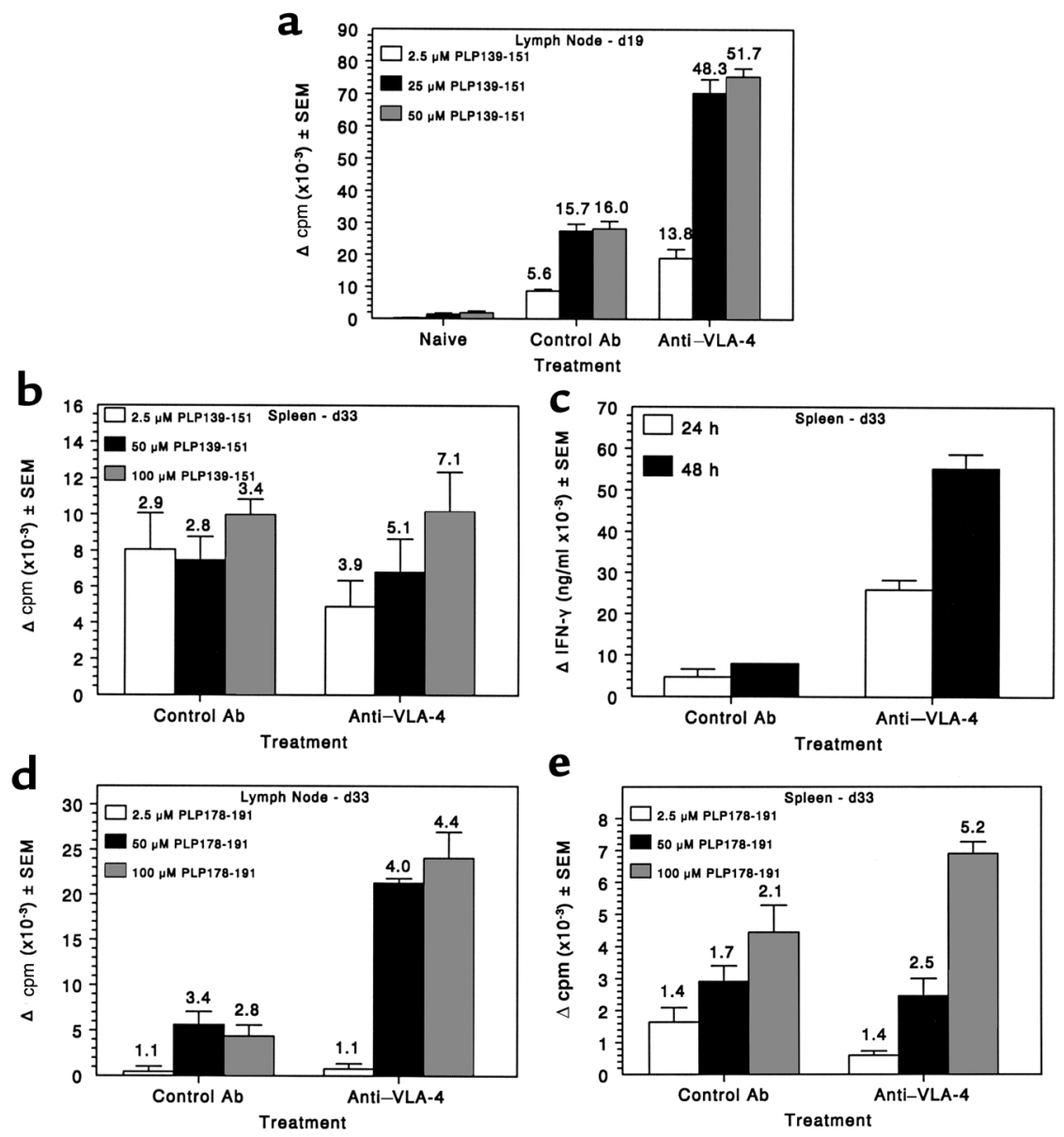

Figure 5

Administration of anti-VLA-4 during ongoing R-EAE enhances proliferation and cytokine production to PLP139-151 and enhances epitope spreading to the relapse-associated PLP178-191 epitope. Spleen and lymph node cells from three mice per group were harvested at both 19 and 33 days after immunization from the experiment indicated in Figure $1 \mathrm{c}$. (a) Viable lymph node cells $\left(5 \times 10^{5} /\right.$ well) from mice at day 19 after immunization (these mice had received three treatments with PS/2 beginning on day 14) were cultured with indicated concentrations of PLP139-151 for 4 days and proliferation was assessed by incorporation of ${ }^{3} \mathrm{H}-\mathrm{TdR}$. ${ }^{3} \mathrm{H}-\mathrm{TdR}$ incorporation in cultures containing medium only were $1874 \pm 286$ and $1488 \pm 334$ for control and anti-VLA-4 groups, respectively. (b) Viable spleen cells $\left(5 \times 10^{5} /\right.$ well) from mice at day 33 after immunization (these mice had received nine treatments with PS/2 beginning on day 14) were cultured with indicated concentrations of PLP139-151 for 4 days and proliferation assessed by incorporation of ${ }^{3} \mathrm{H}-\mathrm{TdR} .{ }^{3} \mathrm{H}-\mathrm{TdR}$ incorporation in cultures containing medium only was 4,199 \pm 306 and 1,662 \pm 248 for control and anti-VLA-4 groups, respectively. (c) Supernatants from the day 33 splenocyte cultures were harvested at 24 and 48 hours and analyzed for IFN- $\gamma$ secretion by ELISA as described in Methods. Proliferative responses at day 33 after immunization to the relapse-associated PLP178-191 epitope were assessed from the lymph nodes (d) and the spleen (e). For d, ${ }^{3} \mathrm{H}-$ TdR incorporation in cultures containing medium only was 2,214 \pm 221 and 6,993 $\pm 1,274$ for control and anti-VLA-4 groups, respectively. In e, medium-only ${ }^{3} \mathrm{H}-\mathrm{TdR}$ incorporation was 4,199 \pm 306 and 1,662 \pm 248 for control and anti-VLA-4 groups, respectively. 
a

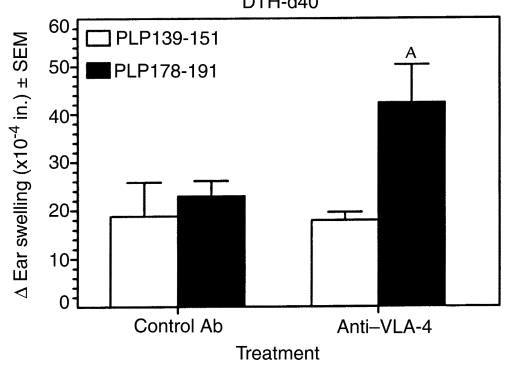

b

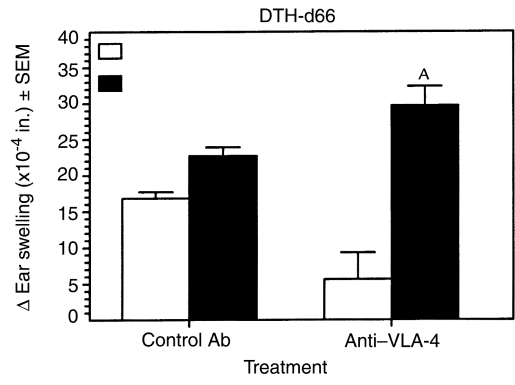

\section{Figure 6}

Mice treated with anti-VLA-4 during disease remission display increased autoantigen-specific Th1 responses to spread epitopes. DTH to PLP178-191, responses to which are associated with the primary relapse, and to MBP84-104, responses to which are associated with the second relapse peptide, were evaluated in mice treated with control Ig or anti-VLA-4 at day 40 (a) and/or day 66 (b) after immunization. Data represent mean \pm SEM of the change in ear thickness 24 hours after ear challenge with $10 \mu \mathrm{g}$ peptide. ${ }^{A} D T H$ responses of the PS/2treated mice were significantly greater than those of the control Ig-treated mice; $P<0.05$.

flow cytometry in the spleen (data not shown). By day 33, when PS/2-treated mice began to show signs of exacerbated R-EAE (Figure 1c), splenic PLP139151 -specific proliferation appears relatively unaffected (Figure 5b), however IFN- $\gamma$ secretion (Figure 5c) was increased substantially over that of controls. Proliferation in both the lymph node and the spleen to the primary relapse-associated PLP178-191 epitope $(5,6)$ was equivalent or slightly higher in the PS/2treated animals (Figures 5, d and e).

Augmentation of ongoing disease, relapse rate, and epitope spreading was also noted in mice in which PS/2 treatment was initiated on day 24 during remission from acute disease. (Figures 1, d and e). PLP178191-specific DTH responses were significantly increased at day 40 over that of the control-treated mice (Figure 6a), but had declined at day 66. However, responses to the epitope associated with the second relapse, MBP84-104 (6), were significantly increased over controls at day 66 (Figure 6b). In summary, treatment with the anti-VLA- $4 \mathrm{mAb}$ PS/ 2 initiated after the appearance of clinical symptoms, either at the peak of acute phase or during remission, increased PLP139151-specific Th1 responses, accelerated epitope spreading, and exacerbated disease relapses. These animals also exhibited significantly enlarged axillary lymph nodes compared with those of control animals.

Acute-phase treatment with anti-VLA-4 enhances lymphoid cell infiltration, expression of VCAM-1, and proinflammatory cytokine $m R N A$ in the CNS. Immunohistochemical analysis of spinal cords on day 19 after priming from mice that had received three injections of anti-VLA- 4 beginning at the peak of acute disease (Figure 1c, day 14) exhibited little difference in $\mathrm{CD}^{+}$and $\mathrm{CD}^{+}$cellular entry into the CNS when compared with controls, with both groups showing the expected decline in cellular infiltration coincident with remission of clinical symptoms (data not shown). However, at day 33 after priming, when PS/2-treated mice are relapsing more severely than controls (Figure 1c) and have just received the last of the nine $\mathrm{Ab}$ injections, influx of $\mathrm{CD}^{+} \mathrm{T}$ cells into the spinal cords of the PS/2-treated animals was markedly enhanced compared with controls (Figure 7, b vs. a). This pattern was observed in multiple spinal cord sections from separate animals. In addition to the white matter mononuclear cell infiltration seen in control-treated mice, $\mathrm{CD} 4^{+} \mathrm{T}$ cells penetrated into the gray matter of anti-VLA-4-treated mice (Figure 7b). Elevated CNS counts of $\mathrm{B} 220^{+}$lymphocytes and $\mathrm{CD}^{+} \mathrm{T}$ cells were also observed in anti-VLA-4-treated animals. Interestingly, VCAM-1 expression was also significantly increased at this time in PS/2-treated mice (Figure $7 d)$ compared with that of control animals (Figure 7c), but P-selectin expression was only slightly enhanced (data not shown). Naive animals showed very little or no expression of CD4, CD8, B220, and VCAM-1 in the CNS. RT-PCR analysis of cytokine mRNA levels at day 33 after priming in the CNS of mice treated with PS/ 2 beginning at the peak of acute disease (day 14) revealed a significant increase in expression of IFN- $\gamma$, while TNF- $\alpha$ and P-selectin levels were similar to that of controls (data not shown).

Anti-VLA-4 can costimulate T-cell proliferation. To investigate the potential role of anti-VLA-4-mediated costimulation in contributing to the enhanced epitope spreading and clinical disease noted in mice treated after disease onset, proliferative responses of naive $\mathrm{BALB} / \mathrm{c}$ splenic $\mathrm{T}$ cells stimulated with polystyrene beads coated with anti-CD3, anti-CD28, and/or antiCD49d Ab's were examined. As shown in Figure 8a, the addition of anti-CD49d to anti-CD3/anti-CD28-coated polystyrene beads induced significantly greater proliferation than cells stimulated with anti-CD3/antiCD28 alone. In addition, anti-VLA-4 coated on separate beads enhanced stimulation induced by beads coated with a combination of anti-CD3/CD28, indicating that anti-VLA- 4 can deliver a costimulatory signal in trans (Figure 8b).

\section{Discussion}

Previous studies have shown the immunotherapeutic potential of anti-VLA-4 mAbs and inhibitors in mul- 
tiple inflammatory diseases based on the importance of VLA-4/VCAM-1 interactions in homing of activated $\mathrm{T}$ cells to inflamed tissues (29). These models include spontaneously occurring diabetes in the NOD mouse (30), asthma (31), and conjunctivitis (32). VLA4 also has been shown to play an integral part in allograft rejection (33), and Ab's targeting it and other adhesion molecules have been the focus of attempts to induce immunosuppression in transplant recipients (34). Furthermore, anti-VLA-4 mAbs have been shown to inhibit lymphocytic interstitial pneumonia in pediatric AIDS patients (35). Several previous reports have also indicated the efficacy of anti-VLA-4 $\mathrm{mAbs}$ in inhibiting active and adoptive EAE when administered at disease induction (7-10). It has also been reported that ant-VLA-4 can inhibit short-term progression of ongoing EAE (25). Because VLA-4 has been reported to be important in other immune functions, including costimulation, induction of matrix metalloproteinases, and apoptosis, we sought to examine specifically the effects of anti-VLA-4 on ongoing R-EAE as a more clinically relevant test of its possible therapeutic potential in treating human autoimmune diseases.

In corroboration of previous studies (7-10), our results indicate that preclinical treatment with anti-VLA-4, either 7 days after PLP139-151/CFA prim- ing (Figure 1a) or treatment of adoptive recipients of primed encephalitogenic $T$ cells (Figure 2), results in transient blockade of clinical disease expression and diminution of trafficking of $\mathrm{CD}^{+} \mathrm{T}$ cells into the $\mathrm{CNS}$ (Figure 3). We further demonstrate that although clinical disease is blocked by anti-VLA-4 treatment begun after peptide priming but before disease onset, peripheral activation of IFN- $\gamma$ and IL- 2 production by Th1 cells is not inhibited and, in fact, is enhanced by the $\mathrm{mAb}$ treatment (Figure 4).

In contrast to the ameliorating effect of preclinical treatment with anti-VLA-4 on EAE disease symptoms, surprisingly, we found that $\mathrm{Ab}$ treatment during ongoing R-EAE led to marked exacerbation of diseaserelapse rates (Figure 1, $d$ and $f$ ) and augmentation of Th1 responses to both the initiating and relapse-associated myelin epitopes (Figures 5 and 6 ). The finding of significantly increased numbers of $\mathrm{CD} 4^{+} \mathrm{T}$ cells and upregulated expression of VCAM-1 (Figure 7) in the CNS of mice treated during ongoing disease indicates that the migration of activated cells into the CNS may be independent of VLA-4/VCAM-1 interactions once the blood brain barrier is disrupted. The enhanced proliferation and cytokine secretion in response to the initiating PLP139-151 epitope on day 19 in animals treated from day 14 (acute phase) indicates accumulation/retention of activated $\mathrm{T}$ cells in the lymph nodes.
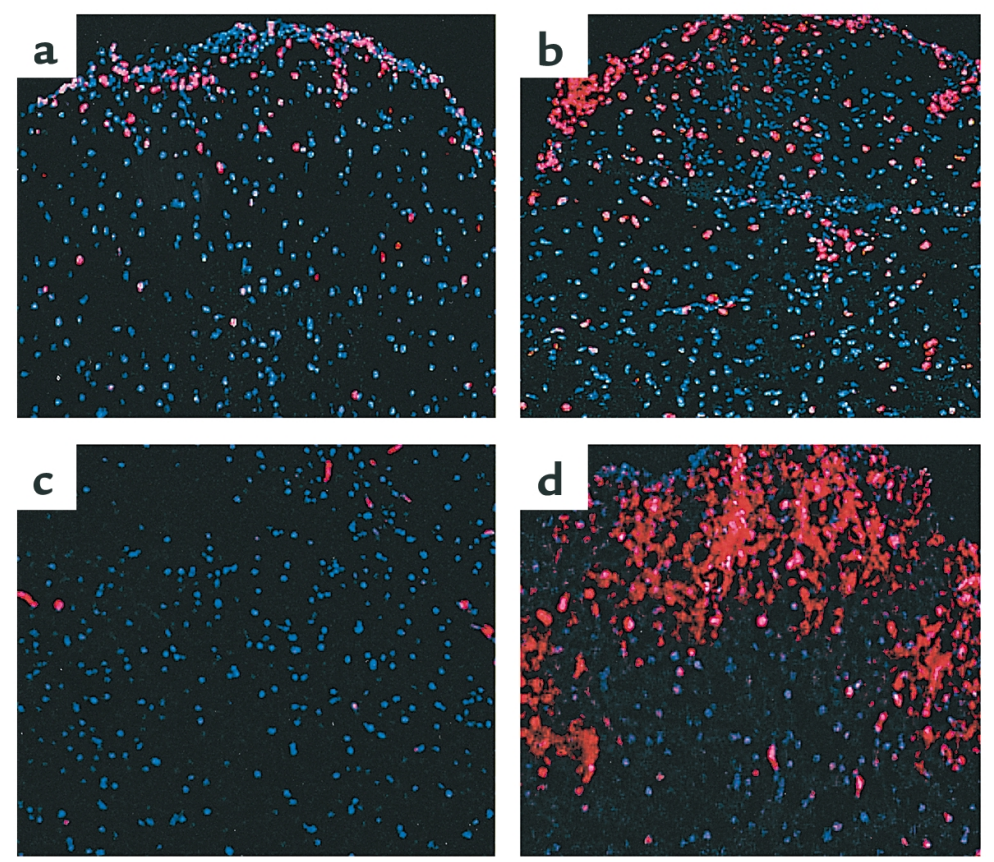

\section{Figure 7}

Administration of anti-VLA-4 during ongoing R-EAE enhances infiltration of CD4 ${ }^{+}$T cells into the CNS and upregulates the expression of VCAM1. Lower thoracic spinal cord tissue sections from representative animals of the treatment groups described in Figure $1 \mathrm{c}$ were examined for infiltration of inflammatory cells on day 33 after immunization. Nine treatments (initiated on day 14) of control Ab or anti-VLA-4 had been given by this time point. Both animals shown had a clinical score of 2 . DAPI, in blue, stains all cells; CD4 $4^{+}$cells and VCAM- 1 are marked in red. (a) Spinal cord CD4 $4^{+}$infiltrate in a control Ab-treated animal. (b) Spinal cord CD4+ infiltrate in an anti-VLA-4-treated animal. (c) Spinal cord VCAM-1 expression in a control Ab-treated animal. (d) Spinal cord VCAM-1 expression in an anti-VLA-4-treated animal. Tissue from a naive animal was tested simultaneously with all three Ab's and revealed the presence of only DAPl ${ }^{+}$(blue) cells. All sections are $6 \mu \mathrm{m}$ thick. $\times 100$. 
a

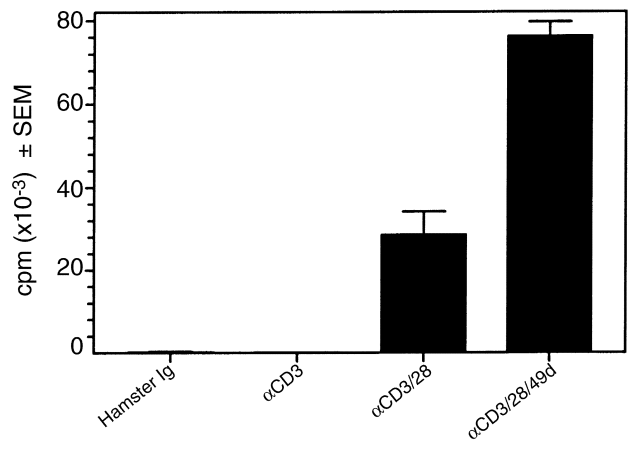

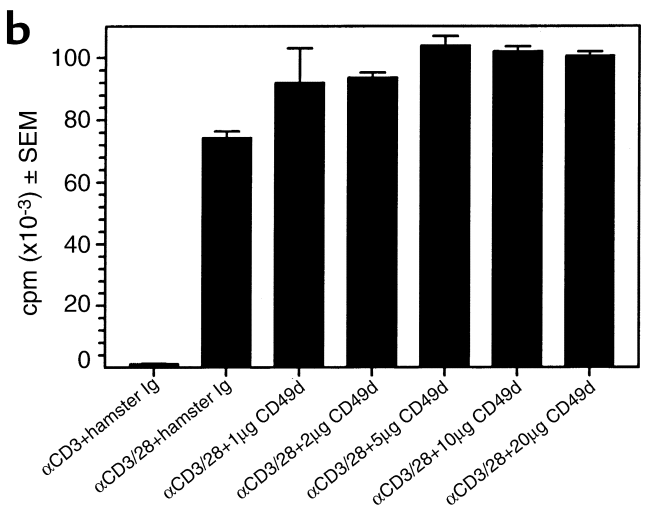

\section{Figure 8}

Anti-VLA-4 can mediate T-cell costimulation in both cis and trans. Naive BALB/c splenic T cells $\left(5 \times 10^{4} /\right.$ well $)$ were cultured in 96 -well microtiter plates with $5-\mu \mathrm{m}$ polystyrene sulfate-coated latex microspheres conjugated with the indicated Ab's as detailed in Methods. Cultures were pulsed with $1 \mu \mathrm{Ci}$ of ${ }^{3} \mathrm{H}-\mathrm{TdR}$ at culture initiation and harvested 72 hours later. (a) The concentrations used for the mAbs were: anti-CD3, $0.5 \mu \mathrm{g} / \mathrm{ml}$; anti-CD28, $20 \mu \mathrm{g} / \mathrm{ml}$; and anti-VLA-4, $2 \mu \mathrm{g} / \mathrm{ml}$. The Ab's were mixed before conjugation to the polystyrene microspheres, and the $\mathrm{Ab}$ concentration in all tubes was normalized to a total of $40 \mu \mathrm{g} / \mathrm{ml}$ using hamster control Ig. (b) Anti-CD3 (0.5 $\mu \mathrm{g} / \mathrm{ml})$ and anti-CD28 $(20 \mu \mathrm{g} / \mathrm{ml})$ were conjugated to polystyrene beads. Separate beads were conjugated with the various indicated concentrations of anti-VLA-4. Naive BALB/c splenic T cells $\left(5 \times 10^{4} /\right.$ well $)$ were cultured with a combination of the anti-CD3/CD28 + anti-VLA-4 beads in a $1: 2$ ratio. Hamster Ig-coated beads were added to anti-CD3 and anti-CD3/28 groups to normalize the total number of beads per well. Similar patterns of proliferation were observed in five separate experiments.

These activated cells can migrate to other peripheral sites during continuous anti-VLA-4 treatment as evidenced by the increased proliferation to the priming epitope in the spleen by day 33. Other studies have shown that mAb's to a number of cellular adhesion molecules and integrins (e.g., CD44, LFA-1, ICAM-1, VCAM-1, and P-selectin) alter trafficking of inflammatory cells to the CNS, demonstrating the complexity of the lymphocyte homing process $(10,36-38)$. In this regard, we are testing currently the effects of Ab's to these additional integrin molecules, alone and in combination, in SJL mice with ongoing R-EAE.

VLA-4-independent migration into the CNS does not, however, explain the increase in T-cell activation peripherally, the increase in the numbers of $\mathrm{T}$ cells in the CNS, or the increase in disease severity in PS/2treated mice compared with controls. If migration into the CNS after the blood-brain barrier is disrupted is VLA-4-independent, treatment with PS-2 should have no effect on chronic disease. The exacerbation of REAE in treated mice may then be related to the ability of VLA-4 to serve as a costimulatory molecule (11-14). Cross-linking of VLA- 4 by PS/ 2 may thus lead to the delivery of costimulatory signals or to the augmentation of other activation signals by enhanced adhesion, which may augment immune responses to the initiating and relapse-associated epitopes. Relapses in PLP139-151-induced R-EAE in the SJL mouse are mediated largely by $\mathrm{T}$ cells specific for endogenous myelin epitopes activated in response to ongoing myelin damage via a process termed epitope spreading $(3,4)$. In fact, our findings that treatment of ongoing disease with anti-VLA-4 leads to increased expansion of Th1 cells specific for relapse-associated epitopes, PLP178-191 and MBP84-104 (Figures 5 and 6), would support this hypothesis. Our recent findings of exacerbated disease relapses in SJL mice treated during REAE remission with an intact $m A b$ to $B 7-1$, which, like VLA-4, is expressed on activated T cells $(39,40)$, is consistent with the possibility that Ab's may provide costimulatory signals in vivo. More direct support for delivery of costimulation by anti-VLA- 4 derives from our current results (Figure 8) demonstrating that VLA4 cross-linking significantly enhances the proliferation of naive $\mathrm{BALB} / \mathrm{c} \mathrm{T}$ cells stimulated with antiCD3/anti-CD28 both in cis and trans, i.e., when the anti-VLA-4 is cross-linked to the same or separate polystyrene beads, respectively.

It could also be argued that this increased disease severity may be due to systemic clearance of the PS/2 due to the induction of anti-rat $\mathrm{Ab}$ responses, resulting in the release of activated cells expressing VLA-4 from the periphery into the CNS. Our data argues against this explanation since PS/ 2 clearance should not lead to the striking increase in T-cell numbers in the CNS and the increased disease severity over that of controls. Also, immunohistochemistry reveals the presence of PS/2 on cells in the CNS of treated mice (data not shown).

Additionally, anti-VLA-4 may be skewing normal Th1/Th2 responses. We and others have reported that disease remission in R-EAE correlates with the expression of Th2 cytokines, including IL-4 and IL-10, suggesting that myelin-specific Th2 responses are important in regulating the pathogenic Th1 responses (27, 41). If the regulatory response mediated by Th2 cells is hindered by anti-VLA-4, persistent accelerated pathogenic Th1 responses could lead to in vivo disease exacerbation. Although the current data do not directly support this hypothesis, peripheral Th2 responses are 
not generally detectable in SJL mice in our hands. However, our preliminary in vitro data suggest that anti-VLA-4 may indeed attenuate responses of Th2 clones (B.E. Theien et al., manuscript in preparation). A role for VLA-4 has been suggested in many effector aspects of the immune response. Expression of MMP-2 is upregulated on VLA-4-expressing T cells after binding to VCAM-1 (42). As MMPs are important in T-cell influx into the CNS (43), it is possible that PS/ 2 cross-linking of VLA-4 on activated T cells may lead to enhanced disruption of the blood-brain barrier by MMP release. Anti-VLA-4 may also lead to enhanced macrophage activation, thus promoting increased CNS damage.

Collectively, our results indicate that caution must be used when attempting to treat established Th1-mediated autoimmune diseases such as MS with intact $\mathrm{mAb}$ to VLA-4 . The exacerbation of R-EAE in animals in which treatment is initiated during the acute phase or during remission with anti-VLA-4 mAb correlated with a dramatic increase in $\mathrm{CD} 4^{+} \mathrm{T}$ cells in the CNS and heightened responses to additional myelin epitopes associated with clinical relapses. We have demonstrated that these results cannot be explained simply by VLA-4-independent migration into the CNS during ongoing disease. Caution regarding the potential use of intact anti-VLA-4 in human disease is also suggested by recent clinical trials on MS patients. Although designed specifically only to examine magnetic resonance imaging (MRI) lesions, relapse rates in patients treated with an anti-VLA-4 mAb were increased over controls, even though the therapy appeared to inhibit short-term development of new MRI lesions (24). However, VLA-4 remains a promising target for therapy in autoimmune diseases, provided monovalent inhibitors can be developed that block homing of activated $\mathrm{T}$ cells without triggering costimulatory and other potential effector activities. Continued examination of the multiple effects anti-VLA-4 and VLA-4 inhibitors have on the immune system will be required to resolve these important issues.

\section{Acknowledgments}

This work was supported by the US Public Health Service NIH grants NS-26543, NS-30871, and NS-34819 and a grant from Biogen Inc.

1. Brown, A.M., and McFarlin, D.E. 1981. Relapsing experimental allergic encephalomyelitis in the SJL/J mouse. Lab. Invest. 45:278-284.

2. McRae, B.L., Kennedy, M.K., Tan, L.J., Dal Canto, M.C., and Miller, S.D. 1992. Induction of active and adoptive chronic-relapsing experimental autoimmune encephalomyelitis (EAE) using an encephalitogenic epitope of proteolipid protein. J. Neuroimmunol. 38:229-240.

3. Lehmann, P.V., Sercarz, E.E., Forsthuber, T., Dayan, C.M., and Gammon, G. 1993. Determinant spreading and the dynamics of the autoimmune T-cell repertoire. Immunol. Today. 14:203-208.

4. McRae, B.L., Vanderlugt, C.L., Dal Canto, M.C., and Miller, S.D. 1995. Functional evidence for epitope spreading in the relapsing pathology of experimental autoimmune encephalomyelitis. J. Exp. Med. 182:75-85.

5. Vanderlugt, C.L., Karandikar, N.J., Bluestone, J.A., and Miller, S.D. 1998. The functional significance of epitope spreading and its regulation by costimulatory interactions. Immunol. Rev. 164:63-72.

6. Vanderlugt, C.L., et al. 2000. Pathologic role and temporal appearance of newly emerging autoepitopes in relapsing experimental autoimmune encephalomyelitis. J. Immunol. 164:670-678.

7. Yednock, T.A., et al. 1992. Prevention of experimental autoimmune encephalomyelitis by antibodies against $\alpha 4 \beta 1$ integrin. Nature. 356:63-66.

8. Kuchroo, V.K., et al. 1992. Experimental allergic encephalomyelitis mediated by cloned $\mathrm{T}$ cells specific for a synthetic peptide of myelin proteolipid protein: fine specificity and $\mathrm{T}$ cell receptor $\mathrm{V}$-beta usage. $J$. Immunol. 148:3776-3782.

9. Baron, J.L., Madri, J.A., Ruddle, N.H., Hashim, G., and Janeway, C.A. 1993. Surface expression of alpha 4 integrin by CD4 $\mathrm{T}$ cells is required for their entry into brain parenchyma. J. Exp. Med. 177:57-68.

10. Brocke, S., Piercy, C., Steinman, L., Weissman, I.L., and Veromaa, T. 1999. Antibodies to CD44 and integrin alpha4, but not L-selectin, prevent central nervous system inflammation and experimental encephalomyelitis by blocking secondary leukocyte recruitment. Proc. Natl. Acad. Sci. USA. 96:6896-6901.

11. Avdalovic, M., Fong, D., and Formby, B. 1993. Adhesion and costimulation of proliferative responses of human gamma delta $\mathrm{T}$ cells by interaction of VLA-4 and VLA-5 with fibronectin. Immunol. Lett. 35:101-108.

12. Sato, T., Tachibana, K., Nojima, Y., D’Avirro, N., and Morimoto, C. 1995. Role of the VLA-4 molecule in T cell costimulation. Identification of the tyrosine phosphorylation pattern induced by the ligation of VLA-4.J. Immunol. 155:2938-2947.

13. Shimizu, Y., Van Seventer, G.A., Horgan, K.J., and Shaw, S. 1990. Costimulation of proliferative responses of resting CD4+ $\mathrm{T}$ cells by the interaction of VLA-4 and VLA-5 with fibronectin or VLA- 6 with laminin. $J$. Immunol. 145:59-67.

14. Van Seventer, G.A., et al. 1991. Analysis of T cell stimulation by superantigen plus major histocompatibility complex class II molecules or by CD3 monoclonal antibody: costimulation by purified adhesion ligands VCAM-1, ICAM-1, but not ELAM-1.J. Exp. Med. 174:901-913.

15. Columbo, M., Bochner, B.S., and Marone, G. 1995. Human skin mast cells express functional beta 1 integrins that mediate adhesion to extracellular matrix proteins. J. Immunol. 154:6058-6064.

16. Silvy, A., Altevogt, P., Mondiere, P., Bella, C., and Defrance, T. 1997. A role for the VLA-4 integrin in the activation of human memory B cells. Eur. J. Immunol. 27:2757-2764.

17. Ohkawara, Y., et al. 1995. In situ expression of the cell adhesion molecules in bronchial tissues from asthmatics with air flow limitation: in vivo evidence of VCAM-1/VLA-4 interaction in selective eosinophil infiltration. Am. J. Respir. Cell Mol. Biol. 12:4-12.

18. Issekutz, A.C. 1998. Adhesion molecules mediating neutrophil migration to arthritis in vivo and across endothelium and connective tissue barriers in vitro. Inflamm. Res. 47(Suppl. 3):S123-S132.

19. Wang, M.W., et al. 1998. Rescue from apoptosis in early (CD34-selected) versus late (non-CD34-selected) human hematopoietic cells by very late antigen 4- and vascular cell adhesion molecule (VCAM) 1-dependent adhesion to bone marrow stromal cells. Cell Growth Differ. 9:105-112.

20. Zaitseva, M.B., Mojcik, C.F., Salomon, D.R., Shevach, E.M., and Golding, H. 1998. Co-ligation of alpha4beta1 integrin and TCR rescues human thymocytes from steroid-induced apoptosis. Int. Immunol. 10:1551-1561.

21. de la Fuente, M.T., Casanova, B., Garcia-Gila, M., Silva, A., and GarciaPardo, A. 1999. Fibronectin interaction with alpha4beta1 integrin prevents apoptosis in B cell chronic lymphocytic leukemia: correlation with Bcl-2 and Bax. Leukemia. 13:266-274.

22. Berlin, C., et al. 1993. $\alpha 4 \beta 7$ integrin mediates lymphocyte binding to the mucosal vascular addressin MAdCAM-1. Cell. 74:185-196.

23. Kanwar, J.R., et al. 2000. $\beta 7$ integrins contribute to demyelinating disease of the central nervous system. J. Neuroimmunol. 103:146-152.

24. Tubridy, N., et al. 1999. The effect of anti-alpha4 integrin antibody on brain lesion activity in MS. The UK Antegren Study Group. Neurology. 53:466-472.

25. Kent, S.J., Karlik, S.J., Rice, G.P., and Horner, H.C. 1995. A monoclonal antibody to alpha 4-integrin reverses the MR-detectable signs of experimental allergic encephalomyelitis in the guinea pig. J. Magn. Reson. Imaging. 5:535-540.

26. Kuchroo, V.K., et al. 1993. Cytokines and adhesion molecules contribute to the ability of myelin proteolipid protein-specific $\mathrm{T}$ cell clones to mediate experimental autoimmune encephalomyelitis. J. Immunol. 151:4371-4382.

27. Begolka, W.S., Vanderlugt, C.L., Rahbe, S.M., and Miller, S.D. 1998. Differential expression of inflammatory cytokines parallels progression of central nervous system pathology in two clinically distinct models of multiple sclerosis. J. Immunol. 161:4437-4446.

28. Leger, O.J., et al. 1997. Humanization of a mouse antibody against human alpha-4 integrin: a potential therapeutic for the treatment of multiple sclerosis. Hum. Antibodies. 8:3-16.

29. McMurray, R.W. 1996. Adhesion molecules in autoimmune disease. Semin. Arthritis Rheum. 25:215-233.

30. Tsukamoto, K., et al. 1995. Administration of monoclonal antibodies against vascular cell adhesion molecule-1/very late antigen- 4 abrogates predisposing autoimmune diabetes in NOD mice. Cell. Immunol. 165:193-201.

31. Lin, K.C., et al. 1999. Selective, tight-binding inhibitors of integrin 
alpha4beta1 that inhibit allergic airway responses. J. Med. Chem. 42:920-934. 32. Ebihara, N., et al. 1999. Anti VLA-4 monoclonal antibody inhibits eosinophil infiltration in allergic conjunctivitis model of guinea pig. Curr. Eye Res. 19:20-25.

33. Coito, A.J., Korom, S., Hancock, W.W., and Kupiec-Weglinski, J.W. 1998 Blockade of alpha 4 beta 1 -integrin-fibronectin adhesive interactions prevents chronic allograft rejection in sensitized recipients. Transplant. Proc. 30:939-940.

34. Socha-Urbanek, K., Urbanek, K., and Fiedor, P. 1998. The role of adhesion molecules in allotransplanted islet cells rejection. Prolongation of islet cells allograft survival by antiadhesion treatment. Ann. Transplant. 3:5-9.

35. Brodie, S.J., et al. 1999. Pediatric AIDS-associated lymphocytic interstitial pneumonia and pulmonary arterio-occlusive disease: role of VCAM1/VLA-4 adhesion pathway and human herpesviruses. Am. J. Pathol. 154:1453-1464.

36. Hori, J., Isobe, M., Yamagami, S., Mizuochi, T., and Tsuru, T. 1997. Specific immunosuppression of corneal allograft rejection by combination of anti-VLA-4 and anti-LFA-1 monoclonal antibodies in mice. Exp. Eye Res. 65:89-98.

37. Irani, D.N., and Griffin, D.E. 1996. Regulation of lymphocyte homing into the brain during viral encephalitis at various stages of infection. $J$. Immunol. 156:3850-3857.

38. Carrithers, M.D., Visintin, I., Kang, S.J., and Janeway, C.A. 2000. Differential adhesion molecule requirements for immune surveillance and inflammatory recruitment. Brain. 123:1092-1101.

39. Miller, S.D., et al. 1995. Blockade of CD28/B7-1 interaction prevents epitope spreading and clinical relapses of murine EAE. Immunity. 3:739-745.

40. Vanderlugt, C.L., et al. 1997. Treatment with intact anti-B7-1 mAb during disease remission enhances epitope spreading and exacerbates relapses in R-EAE. J. Neuroimmunol. 79:113-118.

41. Kennedy, M.K., Torrance, D.S., Picha, K.S., and Mohler, K.M. 1992. Analysis of cytokine mRNA expression in the central nervous system of mice with experimental autoimmune encephalomyelitis reveals that IL-10 mRNA expression correlates with recovery. J. Immunol. 149:2496-2505.

42. Madri, J.A., Graesser, D., and Haas, T. 1996. The roles of adhesion molecules and proteinases in lymphocyte transendothelial migration. Biochem. Cell Biol. 74:749-757.

43. Yong, V.W., Krekoski, C.A., Forsyth, P.A., Bell, R., and Edwards, D.R. 1998. Matrix metalloproteinases and diseases of the CNS. Trends Neurosci. 21:75-80 